\title{
Comparison of the VMONL EMG Activity Ratio According to Resistance Condition in Partial Lunge Exercise
}

\author{
Ki-Seok Nam \\ Department of Physical Therapy, Yeungnam University College, Daegu, Republic of Korea
}

Purpose: The purpose of this study was to investigate the effects of the resistance conditions on the electromyography (EMG) activity ratio of vastus medialis oblique (VMO) and vastus lateralis $(\mathrm{VL})$ muscle during partial lunge exercise in healthy subjects in order to suggest the basic data of exercise intervention for such as patients with patellofemoral pain syndrome (PFPS).

Methods: The participants of this study were healthy twenty two people with no knee pain, limitation of motion and past history of operation at lower extremity. The participants performed three types of lunge 1) no resistance, 2) anterolateral $45^{\circ}$ resistance and 3) lateral $90^{\circ}$ respectively. The EMG activity of the VMO and VL were recorded by surface EMG and the measured data normalized by the \%MVIC value was analyzed by repeated measured ANOVA.

Results: The results showed that the VMONL EMG activity ratio during lunge with anterolateral $45^{\circ}$ resistance was significantly higher than with no resistance and lateral $90^{\circ}$ resistance $(p<0.05)$. There was no significant difference in $\mathrm{VMO}, \mathrm{VL}$, and $\mathrm{VMO} / \mathrm{NL}$ muscle activity between male and female subjects ( $p>0.05$ ).

Conclusion: This study suggests that partial lunge exercise with anterolateral $45^{\circ}$ resistance can increase the VMONL muscle activity in healthy subjects. This result could be used as basic data to develop therapeutic exercise programs such as PFPS patients.

Keywords: VMO/VL ratio, Lunge exercise, Patellofemoral pain

\section{서 론}

무릎넙다리통증증후군(Patellofemoral pain syndrome, PFPS)은 가장 흔한 근골격계 질환 중 하나이며 PFPS의 유병률은 약 $25 \%$ 로 여자에 게 더 흔하게 발생한다.' 현재 PFPS에 대한 원인은 분명하지 않지만 슬 개골 정렬 불량과 근육의 불균형과 같은 비정상적인 생체 역학이 PFPS를 발생시키는 원인중에 하나로 보고있다. 안쪽넓은근(vastus medialis oblique, $\mathrm{VMO}$ )과 가쪽넓은근(vastus lateralis, $\mathrm{VL}$ )은 무릎이 펴 질 때 무릎뼈의 움직임을 조절해주며 VMO와 VL근육에 불균형이 발 생하면 바깥쪽 방향으로 힘의 불균형이 발생하여 무릎벼와 관절의 압력을 높아지고 이러한 현상이 지속되면 통증을 발생하게 된다.-5

PFPS에 대한 물리치료는 무릎뼈 정렬을 위한 $\mathrm{VMO}$ 근육의 선택적 인 강화에 초점을 맞추고 있다. ${ }^{67}$ 선행 연구에서 $\mathrm{VMO}$ 근육의 강화훈 련이 PFPS환자의 통증 감소 및 기능 향상에 효과적이라고 보고하였 다.89 $\mathrm{VMO}$ 근육의 강화훈련은 무릎뼈에 가해지는 힘의 방향이 편향 되는 현상을 개선하는 효과가 있으며, $\mathrm{VMO}$ 근육과 $\mathrm{VL}$ 근육의 균형

Received Mar 5, 2020 Revised Mar 31, 2020

Accepted Apr 14, 2020

Corresponding author Ki-Seok Nam

E-mail seokah@hanmail.net
을 회복하는 것이 PFPS를 치료하는 일반적인 치료목표이다..$^{10}$ 선행 연 구에서 건강한 성인과 PFPS환자들의 운동 시 $\mathrm{VMO} / \mathrm{VL}$ 의 근전도 비 율을 확인하였는데 PFPS환자들의 근전도 비율이 건강한 성인들보 다 낮게 나타났으며, ${ }^{11,12}$ 따라서 근육의 균형을 회복시키기 위해 $\mathrm{VMO} / \mathrm{VL}$ 의 비율을 증가시키는 것을 중요하게 생각하고 있다.

Hanten와 Schulthies ${ }^{13}$ 는 VMO근육을 선택적으로 활성화하기 위 한 방법을 제시하고 그 중요성에 대해 보고하였으며, 여러 연구자들 은 탄성 밴드를 이용하여 근육을 선택적으로 강화시키는 방법을 제 시하였다. Song ${ }^{14}$ 은 41 명의 성인을 대상으로 스쿼트 운동을 실시했는 데 탄성밴드를 이용해 무릎에 적용하는 저항을 다양한 방향으로 적 용하여 근육을 선택적으로 강화시켰다. $\mathrm{Hammer}^{15}$ 의 연구에서도 동 일한 디자인으로 연구를 진행하였는데 두 연구 모두 앞쪽과 뒤쪽 저 항 중 뒤쪽으로 저항을 줄 때 $\mathrm{VMO}$ 근육을 더 선택적으로 강화시킬 수 있다고 하였다. 또한 Coqueiro ${ }^{16}$ 의 연구에서는 기계적인 장치를 이 용하여 다리를 안쪽으로 모으는 힘을 주는 미니 스쿼트를 실시하였 는데 건강한 대상자와 PFPS환자 모두에게서 $\mathrm{VMO} / \mathrm{VL}$ 근육 활성비
Copylight (02020 The Korean Society of Physical Therapy

This is an Open Access article distribute under the terms of the Creative Commons Attribution Non-commercial License (https:// creativecommons.org/license/by-nc/4.0.) which permits unrestricted non-commercial use, distribution, and reproduction in any medium, provided the original work is properly cited. 
율이 더 균형있게 사용되는 것을 확인하였다. Hung와 Gross ${ }^{17}$ 의 연구 에서는 한쪽 다리로 선 자세에서 부분 스퀴트 운동 $\left(0-50^{\circ}\right)$ 시 $\mathrm{VMO} /$ $\mathrm{VL}$ 의 비율이 최대등척성수축시 보다 높은 값을 보였고, Choi와 Lee ${ }^{18}$ 의 연구에서는 15 명의 건강한 남성을 대상으로 런지 운동 시 발목의 벌림 각도에 따른 $\mathrm{VMO} / \mathrm{VL}$ 의 비율을 알아보았는데 발목이 $60^{\circ}$ 벌림 된 자세에서 $\mathrm{VMO}$ 활성도가 가장 증가되었다고 하였다. 본 연구에서 선택한 부분 런지(partial lunge) 운동방법은 다른 하지 운동에 비해 많은 힘을 필요로 하지 않기 때문에 재활 초기에 많은 도움이 될 것이 라고 하였다. ${ }^{19}$

$\mathrm{VMO} / \mathrm{VL}$ 근육 활성비율에 영향을 미치는 운동방법에 관한 다수 의 선행연구가 있었으나 부분 런지 운동 시 무릎관절의 폄동작시에 가해지는 저항의 유무와 방향에 따른 연구는 없었다. 따라서 본 연구 는 건강한 성인을 대상으로 부분 런지 운동 시 저항의 유무와 방향 이 $\mathrm{VMO} / \mathrm{VL}$ 근육의 활성 비율에 어떤 영향을 미치는지를 연구하여 $\mathrm{PFPS}$ 등과 같이 $\mathrm{VMO}$ 의 선택적 활성화가 필요한 환자의 운동치료 프 로그램의 개발에 대한 기초자료를 제공하고자 한다.

\section{연구 방법}

\section{1. 연구대상}

본 연구는 20 대의 건강한 성인 22 명(남성 10 명, 여자 12 명)을 대상으로 하였다. 연구대상의 제외기준은 1) 하지와 몸통에 통증이 있는 자, 2) 몸통과 하지의 관절가동범위가 정상범위에서 현저하게 벗어난 자, 3) 하지 관절의 질환이나 그로 인한수술병력이 있는 자였다(Table 1).

\section{2. 실험방법}

\section{1) 측정도구 및 자료수집}

근전도를 이용하여 근육의 활성도를 측정하기 위해 Noraxon TeleMyo 2400T (Noraxon TeleMyo 2400T, Noraxon Inc., Scottsdale, AZ, USA)를 사용했다. 표면전극 2개를 이용하여 양쪽 무릎의 VMO와 VL 에 근육섬유의 방향과 나란히 부착하였다. 전극을 피부에 부착하기 전에 저항을 최소화하기 위하여 전극을 알코올로 닦았으며, 각 근육 의 전극부착 위치의 털을 제거한 후 알코올로 닦았다. 전극의 부착부 위로서 무릎뼈의 위쪽으로 중앙선을 기준으로 $3-5 \mathrm{~cm}$ 위치에서 안쪽 으로 약 $2 \mathrm{~cm}$ 부위에 $55^{\circ}$ 의 사선으로 $\mathrm{VMO}$ 근육에 전극을 부착하였

Table 1. General characteristics of subjects

$(n=21)$

\begin{tabular}{lcc}
\hline Variables & Mean \pm SD & Range \\
\hline Age $(\mathrm{yr})$ & $20.75 \pm 2.28^{\mathrm{a}}$ & $20-29$ \\
Height $(\mathrm{cm})$ & $169.84 \pm 8.83$ & $154-183$ \\
Weight $(\mathrm{kg})$ & $60.25 \pm 15.27$ & $47-81$ \\
\hline
\end{tabular}

${ }^{a}$ Values are mean $\pm S D$.
고, VL근육의 전극은 무릎뼈의 위쪽 중앙선에서 바깥쪽으로 촉진을 통해 부착하였다. ${ }^{20}$

채널을 지정하여 각 채널에서 근전도 신호를 받을 수 있도록 하였 고, 근전도 신호의 표본추출률은 $1,000 \mathrm{~Hz}$ 로 하였다. 증폭된 파형은 $10-500 \mathrm{~Hz}$ 의 대역통과필터(band pass filter)로 필터링하였다. 잡음을 제거하기 위해 $60 \mathrm{~Hz}$ 노치필터(notch filter)를 설정하였고 각 근육이 수축하는 동안 수집된 신호를 정량화하기 위해 Root Mean Square (RMS)처리를 하였다.

근전도를 이용하여 수집한 근육의 활성도를 정량화(normalization) 하기 위한 기준값으로서 활용하기 위하여 최대수의적등척성수축값 (maximal voluntary isometric contraction, MVIC)을 측정하였다. ${ }^{21}$ $\mathrm{MVIC}$ 의 측정을 위해 대상자에게 테이블에 앉은 상태에서 무릎관절 폄을 유지하도록 지시하면서 실험자는 최대의 힘으로 무릎관절 굽힘 을 약 5 초간 3 회 반복 실시하였으며, 처음과 마지막의 약 1 초를 제외한 중간의 3 초 동안의 평균 근전도값을 $100 \% \mathrm{MVIC}$ 로 하였다.

\section{2) 운동프로그램}

대상자는 사전에 실험자로부터 실험방법에 대한 충분한 설명을 듣고 동의서에 서명을 하였고, 실험의 목적과 결과는 대상자들에게 설명 하거나 제공하지 않았다. 대상자는 반바지를 착용하고 맨발로 지면 에 서서 자신의 우세발을 앞으로 위치시키고 상체는 바로 세운 상태 에서 발목관절은 약 $60^{\circ}$ 벌림자세를 시작자세로 하였다. ${ }^{17}$ 자료수집 을 위한 부분 런지운동을 시도하기 전에 수차례의 연습을 통해 자세 를 교정하여 대상자간 운동 자세의 변이를 방지하였다.

부분 런지동작을 수행하는 동안 무릎에 저항을 적용하기 위해 런 지 시작자세를 취한 후 운동용 풀리시스템(Lojer, Finland)을 이용하 였다. 저항의 적용은 전외측 $45^{\circ}$ 와 외측 $90^{\circ}$ 로 실시하였다. 모든 대상 자는 무저항, 전외측 $45^{\circ}$, 외측 $90^{\circ} 3$ 종류의 부분 런지운동을 실시하 였다. 런지운동 종류별 순서는 랜덤하게 적용하여 순서효과를 최소 화하였으며, 운동 간에는 약 30-60초간 휴식을 취하도록 하여 피로를 최소화하였다. 저항이 적용되는 방향으로 무게중심이 이동하는 현 상을 방지하기 위하여 저항이 적용되는 다리쪽의 외측에 의자를 두 어 가볍게 지지할 수 있도록 허용하였으며 전면에 거울을 배치하여 자세유지를 위한 시각적 피드백을 제공하였다.

런지동작은 약 $50^{\circ}$ 의 무릎굽힘이 될 때까지 몸을 하강했다가 다시 시작자세로 회귀하는 동작을 실시하였으며 3종류의 런지운동별로 3 번씩의 시도를 하였다. ${ }^{18}$

\section{3) 통계방법}

부분 런지 운동 시 저항유무와 방향에 따라서 1) 무저항, 2) 전외측 $\left.45^{\circ}, 3\right)$ 외측 $90^{\circ}$ 에 따른 $\mathrm{VMO}$ 와 $\mathrm{VL}$ 근육의 근전도 활성도 그리고 
Table 2. Comparison of the muscle activity according to lunge conditions

(unit: \%MVIC)

\begin{tabular}{lrrrcc}
\hline Muscle & No resistance & 45 resistance & 90 resistance & $F$ & $p$ \\
\hline VMO & $47.75 \pm 18.12$ & $58.02 \pm 19.71$ & $46.45 \pm 16.83$ & 2.746 & 0.087 \\
VL & $43.19 \pm 17.24$ & $47.02 \pm 17.81$ & $41.12 \pm 18.29$ & 0.691 & 0.722 \\
VMONL & $111.71 \pm 21.59$ & $125.31 \pm 20.74$ & $113.16 \pm 24.75$ & 4.949 & $0.011^{*}$
\end{tabular}

Values are mean $\pm S D$.

${ }^{*} p<0.05$.

$\mathrm{VMO} / \mathrm{VL}$ 근육의 근전도 활성도의 비를 비교하기 위하여 반복측정에 의한 분산분석(repeated measures ANOVA)과 대비검증을 실시하였 다. 통계적 유의수준 $\alpha=0.05$ 로 하였다.

\section{결 과}

\section{1. 부분 런지운동시 저항유무와 방향에 따른 $\mathrm{VMO}, \mathrm{VL}$ 그리고 $\mathrm{VMO} / \mathrm{VL}$ 근활성도(\%MVIC)}

부분 런지운동을 하는 동안 저항의 유무와 방향에 따른 3 가지의 부 분 런지 즉 무저항, 전외측 $45^{\circ}$, 외측 $90^{\circ}$ 의 조건에 따른 $\mathrm{VMO}, \mathrm{VL}$ 그리 고 $\mathrm{VMO} / \mathrm{VL}$ 의 $\% \mathrm{MVIC}$ 를 비교한 결과 $\mathrm{VMO}$ 와 $\mathrm{VL}$ 의 근활성도는 차 이가 없었고, $\mathrm{VMO} / \mathrm{VL}$ 근활성도 비율은 통계적으로 유의한 차이가 있었다. 부분 런지 조건을 요인으로 한 대비검증을 실시한 결과 전외 측 $45^{\circ}$ 런지의 경우 $\mathrm{VMO} / \mathrm{VL}$ 이 무저항과 외측 $90^{\circ}$ 런지에 비하여 통 계적으로 유의하게 증가한 결과를 보였다. 전체 대상자중에서 남성 과 여성의 $\mathrm{VMO}, \mathrm{VL}$ 그리고 $\mathrm{VMO} / \mathrm{VL}$ 의 \%MVIC를 비교한 결과 통계 적으로 유의한 차이가 없었다( $\mathrm{p}>0.05)($ Table 2).

\section{고 찰}

본 연구는 부분 런지 운동 시 저항의 유무와 방향이 $\mathrm{VMO} / \mathrm{VL}$ 근육 활성 비율에 미치는 영향을 알아보고자 표면근전도를 이용하여 실시 하였다. 저항을 적용한 런지 운동과의 비교를 위해 저항 없는 런지도 함께 실시하였다. 저항의 방향은 전외측 $45^{\circ}$ 와 외측에서 탄성밴드를 이용하여 한쪽 다리에 저항을 적용하였으며 저항에 따른 균형을 유 지하도록 하기 위해 저항이 가해지는 다리의 옆에 의자를 두어 가벼 운 지지를 허용하면서 실험을 진행하였다. 연구의 결과 저항을 주지 않았을 때와 외측 $90^{\circ}$ 방향에서 저항을 준 것에 비해 전외측 $45^{\circ}$ 방향 에서 저항을 주었을 때 $\mathrm{VMO} / \mathrm{VL}$ 의 근육 활성 비율이 높게 나타났다.

PFPS환자들의 재활프로그램으로 닫힌 사슬 운동이 효과적이라 고 제안되고 있으며 $\mathrm{VMO} / \mathrm{VL}$ 의 근육 활성 비율과 넙다리네갈래근 의 근육활동 증가에 도움이 된다는 연구가 있다. 2,22 무릎 폄 닫힌 사 슬 운동은 대퇴사두근을 수축시켜 무릎 관절의 안정성을 향상시킨 다. 그리고 운동을 적용할 때 자세나 방법에 따라 근활성도가 달라질
수 있다고 여러 연구에서 제안하고 있으며 스쿼트 운동 시 스쿼트 범 위, 런지 운동 시 발목 관절의 각도를 조절하여 근육 활동 증가에 효 과적이다는 연구가 있었다. ${ }^{17,18}$ 따라서 본 연구에서는 $\mathrm{VMO}$ 근육의 활 성 비율을 증가시키기 위한 운동처치법으로서 무릎 폄 운동시 저항 의 유무와 방향을 설정하였다. ${ }^{1718}$ 본 연구에서 저항을 적용하지 않은 경우와 외측 $90^{\circ}$ 방향에서 저항을 적용했을 때 유의한차이가 나타나 지 않았는데, Souza ${ }^{11}$ 는 런지 운동은 기본적으로 $\mathrm{VMO}$ 와 $\mathrm{VL}$ 근육의 비율을 거의 동일하게 사용하는 운동이라고 하였으며, Coqueiro ${ }^{16}$ 는 안쪽으로 힘을 주며 하지의 운동을 할 때 $\mathrm{VMO}$ 와 $\mathrm{VL}$ 의 비율이 균형 을 이루었다는 점에서 본 연구도 유사한 결과를 보여주었다. 외측 $90^{\circ}$ 방향의 저항을 받으며 런지를 하는 것은 엉덩관절의 모음을 동반하 여 런지를 하였다고 볼 수 있는데 이 때 선택적으로 $\mathrm{VMO}$ 를 활성시키 지 못하고 VL과 유사하게 나타나는 것은 Laprade의 연구 결과와 일 치하였다.23

전외측 저항을 적용한 상태에서의 런지 운동을 실시한 경우 저항 이 없을 때와 외측에서 저항을 적용했을 때보다 $\mathrm{VMO}$ 근육이 선택적 으로 활성화 된 결과를 보여주었는데 이 결과는 Hertel의 연구결과와 동일하였으며, ${ }^{24}$ 이는 엉덩관절의 모음근육과 폄근육을 모두에게 저 항을 주어 $\mathrm{VMO} / \mathrm{VL}$ 의 근육 활성 비율을 증가시킨 것으로 사료된 다. ${ }^{25}$

본 연구는 물리치료 임상현장에서 자주 마주하는 PFPS환자의 $\mathrm{VMO}$ 근육을 선택적으로 활성화시키는 방법을 알아보기 위해 연구 한 결과 전외측 $45^{\circ}$ 방향에서 저항을 적용한 상태에서 런지를 할 때 가장 효과적인 것으로 나타났다. 이 결과는 $\mathrm{VMO} / \mathrm{VL}$ 근육 활성 비율 을 높일 수 있는 효과적인 운동 방법이며 특히 근력이 부족한 재활 초기의 환자에게 적용하기에 효과적이란 점에서 임상적 의의가 있다.

본 연구는 건강한 성인을 대상으로 부분런지 운동 시 무저항, 전외 측 $45^{\circ}$ 저항, 외측 $90^{\circ}$ 저항을 적용하여 $\mathrm{VMO} / \mathrm{VL}$ 근육 활성 비율에 미 치는 영향을 알아보고자 실시하였다. 무저항과 외측 $90^{\circ}$ 방향에서 저 항을 적용했을 때보다 전외측 $45^{\circ}$ 방향에서 저항을 적용한 런지 운동 시 $\mathrm{VMO} / \mathrm{VL}$ 근육 활성(\%MVIC) 비율을 증가시키는 것으로 나타났 다. 이는 임상에서 자주 마주하는 무릎넙다리통증증후군 환자에게 효과적인 운동의 방법을 제시할 수 있는 기초자료가 될 것이며 근력 이 약한 재활 초기의 환자들에게 도움이 될 것이라 생각한다. 본 연 구를 바탕으로 실제 무릎넙다리통증증후군 환자를 대상으로 한 임 상 연구가 지속되어야 할 것으로 사료된다.

\section{REFERENCES}

1. Boling M, Padua D, Marshall S et al. Gender differences in the incidence and prevalence of patellofemoral pain syndrome. Scand J Med Sci Sports. 2010;20(5):725-30. 
2. Chang WD, Chen FC, Lee CL et al. Effects of Kinesio taping versus McConnell taping for patellofemoral pain syndrome: a systematic review and meta-analysis. Evid Based Complement Alternat Med. 2015.

3. Mohr KJ, Kvitne RS, Pink MM et al. Electromyography of the quadriceps in patellofemoral pain with patellar subluxation. Clin Orthop Relat Res. 2003;415:261-71.

4. Chang WD, Huang WS, Lai PT. Muscle activation of vastus medialis oblique and vastus lateralis in sling-based exercises in patients with patellofemoral pain syndrome: a cross-over study. Evid Based Complement Alternat Med. 2015.

5. Clouthier A, Borschneck D, Thelen DG et al. Relationship between lateral patellar stability following tibial tubercle osteotomy for varying patellofemoral geometries. J Biomech Eng. 2019.

6. Chen S, Chang WD, Wu JY et al. Electromyographic analysis of hip and knee muscles during specific exercise movements in females with patellofemoral pain syndrome: an observational study. Medicine (Baltimore). 2018;97(28):e11424.

7. Glaviano NR, Saliba S. Differences in gluteal and quadriceps muscle activation during weight-bearing exercises between female subjects with and without patellofemoral pain. J Strength Cond Res. 2019.

8. Hodges P, Richardson C. The influence of isometric hip adduction on quadriceps femoris activity. Scand J Rehabil Med. 1993;25(2):57-62.

9. Barton C, Balachandar V, Lack S et al. Patellar taping for patellofemoral pain: a systematic review and meta-analysis to evaluate clinical outcomes and biomechanical mechanisms. Br J Sports Med. 2014;48(6):417-24.

10. Miao P, Xu Y, Pan C et al. Vastus medialis oblique and vastus lateralis activity during a double-leg semisquat with or without hip adduction in patients with patellofemoral pain syndrome. BMC Musculoskelet Disord. 2015;16:289.

11. Souza DR, Gross MT. Comparison of vastus medialis obliquus: vastus lateralis muscle integrated electromyographic ratios between healthy subjects and patients with patellofemoral pain. Phys Ther. 1991;71(4): 310-6.

12. Powers CM. Patellar kinematics, part I: the influence of vastus muscle activity in subjects with and without patellofemoral pain. Phys Ther. 2000;80(10):956-64.

13. Hanten WP, Schulthies SS. Exercise effect on electromyographic activity of the vastus medialis oblique and vastus lateralis muscles. Phys Ther. 1990;70(9):561-5.
14. Song JE, Choi HS, Shin WS. Effect of applying resistance in various directions on lower extremity muscle activity and balance during squat exercise. Phys Ther Rehab Sci. 2019;8(2):61-6.

15. Hammer WI. Functional soft-tissue examination and treatment by manual methods. Jones \& Bartlett Learning. 2007.

16. Coqueiro KRR, Bevilaqua-Grossi D, Bérzin F et al. Analysis on the activation of the VMO and VLL muscles during semisquat exercises with and without hip adduction in individuals with patellofemoral pain syndrome. J Electromyogr Kinesiol. 2005;15(6):596-603.

17. Choi Y, Lee S. Changes in lower limb muscle activity based on angle of ankle abduction during lunge exercise. J Phys Ther Sci. 2017;29(11): 1947-9.

18. Hung Y, Gross M. Effect of foot position on EMG activity of VMO and VL during lower-extremity weight bearing activities. Journal of Orthop Sports Phys Ther. 1999;29:93-105.

19. Irish SE, Millward AJ, Wride J et al. The effect of closed-kinetic chain exercises and open-kinetic chain exercise on the muscle activity of vastus medialis oblique and vastus lateralis. J Strength Cond Res. 2010;24(5): 1256-62.

20. Cram J, Kasman G, Holtz J. Introduction to surface electromyography, Ed. Gaithersburg. Maryland: Aspen Publication ${ }^{\circledR}$. 1998. Criswell E. Cram's Introduction to Surface Electromyography. Jones \& Bartlett Learning. 1998.

21. Newman S, Jones G, Newham D. Quadriceps voluntary activation at different joint angles measured by two stimulation techniques. Eur J Appl Physiol. 2003;89(5):496-9.

22. Peng HT, Kernozek TW, Song CY. Muscle activation of vastus medialis obliquus and vastus lateralis during a dynamic leg press exercise with and without isometric hip adduction. Phys Ther Sport. 2013;14(1):44-9.

23. Laprade J, Culham E, Brouwer B. Comparison of five isometric exercises in the recruitment of the vastus medialis oblique in persons with and without patellofemoral pain syndrome. J Orthop Sports Phys Ther. 1998;27(3):197-204.

24. Hertel J, Earl J, Tsang K et al. Combining isometric knee extension exercises with hip adduction or abduction does not increase quadriceps EMG activity. Br J Sports Med. 2004;38(2):210-3.

25. Hammer W. Functional soft tissue examination and treatment by Manual methods, Ed 3. Gaithersburg, MD. Aspen Publishers Inc. 1999. 